\title{
Formation of the circle of Willis during human embryonic development
}

\author{
$\operatorname{AUTHOR}(\mathrm{S}):$ \\ Takakuwa, Tetsuya; Koike, Teppei; Muranaka, \\ Taiga; Uwabe, Chigako; Yamada, Shigehito
}

\section{CITATION:}

Takakuwa, Tetsuya ...[et al]. Formation of the circle of Willis during human embryonic development. Congenital Anomalies 2016, 56(5): 233-236

ISSUE DATE:

2016-09-01

URL:

http://hdl.handle.net/2433/216971

\section{RIGHT:}

This is the accepted version of the following article: [Takakuwa, T., Koike, T., Muranaka, T., Uwabe, C., and Yamada, S. (2016) Formation of the circle of Willis during human embryonic development. Congenital Anomalies, 56: 233-236.], which has been published in final form at http://dx.doi.org/10.1111/cga.12165. This article may be used for noncommercial purposes in accordance with Wiley Terms and Conditions for Self-Archiving.; The full-text file will be made open to the public on 1 September 2017 in accordance with publisher's 'Terms and Conditions for Self-Archiving'.; This is not the published version. Please cite only the published version.; この論文は出版社版でありません。引用の際には 出版社版をご確認ご利用ください。 
Short communication

Formation of the circle of Willis during human embryonic development

Takakuwa

Short title: Formation of the CW

Tetsuya Takakuwa ${ }^{1}$, Teppei Koike ${ }^{1}$, Taiga Muranaka ${ }^{1}$, Chigako Uwabe ${ }^{2}$, Shigehito Yamada $^{1,2}$

1) Human Health Science, Graduate School of Medicine, Kyoto University, Kyoto, Japan

2) Congenital Anomaly Research Center, Graduate School of Medicine, Kyoto University, Kyoto, Japan

Corresponding author: Dr. Tetsuya Takakuwa,

Human Health Science, Graduate School of Medicine, Kyoto University

606-8507 Sakyo-ku Shogoin Kawahara-cyo 53, Kyoto, Japan

E-mail; tez@hs.med.kyoto-u.ac.jp,TEL; +81-75-751-3931 


\section{Abstract}

The circle of Willis (CW) is a circulatory anastomosis that supplies blood to the brain and adjacent structures. We examined the timing of formation of $\mathrm{CW}$ in 20 Japanese human embryo samples by using 3-dimensional reconstruction of serial histological sections. The CW was closed in $1(n=6), 2(n=8), 2(n=3)$ and $2(n=3)$ samples at Carnegie stages $20,21,22$, and 23 , respectively. The CW was unclosed in 13 samples (unclosed at ACOM alone, 6 samples; ACOM and bilateral P1, 4; left PCOM and right $\mathrm{P} 1,1$; right $\mathrm{PCOM}$ and right $\mathrm{P} 1,1$; $\mathrm{ACOM}$ and left $\mathrm{PCOM}, 1)$. It was difficult to predict whether the circle would close during further development, as such variations frequently exist in adults.

\section{Key Words}

Circle of Willis, human embryo, three-dimensional reconstruction 


\section{Introduction}

The circle of Willis (CW), also called Willis' circle or cerebral arterial circle, is a

circulatory anastomosis that supplies blood to the brain and adjacent structures (Eastcott 1994). The CW is composed of the following arteries: left and right anterior cerebral arteries (ACA), anterior communicating artery (ACOM), internal carotid arteries (ICA), posterior cerebral arteries (PCA), posterior communicating arteries (PCOM), and basilar artery (BA). As the CW serves the important function of providing blood supply to the brain, it communicates with multiple collaterals in the cerebral circulation. Willis recognized these anastomoses as a compensatory system to overcome any arterial occlusion. The presence of collateral flow via the PCOM in the CW is associated with a low prevalence of border zone infarcts in patients with unilateral ICA occlusion (Hendrikse et al. 2001). A recent simulation study demonstrated that the CW served as a passive pressure dissipating system under physiologic conditions, implying that the $\mathrm{CW}$ and its communicating arteries protect the cerebral arteries and the blood-brain barrier from hemodynamic stress (Vrselja et al. 2014).

The CW has many variations. The complete circle was observed in only $5-28 \%$ of adults. Variations at the ACOM, PCOM, and precommunicating segment 
(segment P1) of the PCA are well known. ACOM aplasia or hypoplasia was observed in $5-32 \%$ of the total examined adult cases, PCOM aplasia or hypoplasia was observed in 23-81\%, and segment P1 aplasia or hypoplasia was observed in 7-15\% (Alpers et al. 1959; Eftekhar et al. 2006; Fisher 1965; Fujimoto \& Tanaka 1989).

Cerebral aneurysms that result in intracranial hemorrhage (subarachnoid hemorrhage) frequently occur in the CW. Cerebral aneurysms are associated with various pathological cerebrovascular conditions responsible for hemodynamic changes (Dyste \& Beck 1989). Variations in the CW have a direct impact on the distribution of carotid and basilar blood flow and the formation of aneurysms (Horikoshi et al. 2002; Kayembe et al. 1984; Kirgis et al. 1966; Kwak et al. 1980). There are other cerebrovascular disorders (Hendrikse et al. 2001; Schomer et al. 1994) and mental disorders that may also be associated with these variations (Blackburn 1907, 1910).

Padget (1948) was the first person to precisely describe the embryonic development of the human brain vasculature. In her study, development of the intracranial artery, including CW, was fully described in 19 human embryonic samples between Carnegie stages (CS) 13 and 21, one fetal sample (crown-rump length, $C R L=$ $40 \mathrm{~mm}$ ), and one adult sample. Padget also demonstrated that the circle was unclosed 
in 2 samples at CS 18 and CS 19, whereas closed in all 3 samples at CS 20 and all 3 samples after CS 21. Among the 3 samples at CS 20, ACOM had a plexiform appearance in two samples, and a single main artery in one sample. No other studies have provided such a precise description of the development of the $\mathrm{CW}$ in the embryonic period of humans to date.

In the present study, we examined the timing of formation of CW in Japanese human embryo samples by using 3-dimensional (3-D) reconstruction of serial histology sections.

\section{Materials and Methods}

\section{Human embryo specimens}

Approximately 44,000 human embryos comprising the Kyoto Collection are stored at the Congenital Anomaly Research Center of Kyoto University (Nishimura et al. 1968; Shiota 1991; Yamada et al. 2004). Well-preserved human embryos that were found to be normal on external appearance were subjected to serial sectioning for histology. For this study, 20 Japanese human embryos between CS 20 and CS 23 were selected from the Kyoto Collection. All the selected samples exhibited no overt damage or anomalies, and the histological specimens were well preserved. 


\section{Digitalization of histological sections and $3 D$ reconstruction of $C W$}

Serial sections (transverse sections, $10 \mu \mathrm{m}$ thick) of whole embryos were scanned and stored as digital data by using a film scanner (CanoScan 9000F, Canon, Tokyo, Japan) at $4800 \mathrm{dpi}$. Sequential 2-D images were trimmed digitally by using ImageJ 64-bit (ver. 1.46, National Institutes of Health, Bethesda, MD, USA) and saved in Microsoft Windows Bitmap Image files (.bmp) at a resolution identical to that of the original digital data. The cranial arteries, including $\mathrm{CW}$, were segmented on serial digital sections, and 3-D images were computationally reconstructed for examining the morphology by using Amira software (ver. 5.5.0, Visage Imaging, Berlin, Germany) in all samples. The ethics committee of the Kyoto University Graduate School and Faculty of Medicine approved this study (E986).

\section{Results}

A total of 20 samples were analyzed. The CW was closed in $1(n=6), 2$ $(n=8), 2(n=3)$, and $2(n=3)$ samples at Carnegie stages $20,21,22$, and 23 , respectively (Figure 1, Table 1). The CW was unclosed in 13 samples, 6 at ACOM alone, 4 at ACOM and bilateral $\mathrm{P} 1$, one at right $\mathrm{PCOM}$ and right $\mathrm{P} 1$, one at left $\mathrm{PCOM}$ and right $\mathrm{P} 1$, and one at the ACOM and left PCOM (Figure 2). ACOM occasionally had a plexiform 
appearance (Figure 1, reconstruction at CS 22).

\section{Discussion}

The study by Padget (1948) remains unmatched in its precision in reporting the

development schedule of the formation of $\mathrm{CW}$ during the embryonic period. Thus, the schedule described in that study is the only one available worldwide. Padget's study demonstrated that the $\mathrm{CW}$ forms a closed circle at CS 20 to coincide with the formation of the ACOM. The results of our study deviate from Padget's findings in suggesting a delay of one or two stages in the schedule of formation of the CW. Racial differences may one possible explanation of the difference in timing noted in the two studies.

Previous studies reviewed the distribution of the $\mathrm{CW}$ variation in different populations (Eftekhar et al. 2006; Hashemi et al. 2013). They are very cautious to the conclusion that the distributions of the variations of cerebral arterial circle differ in different populations. Padget has reported many variations in adults samples (Padget 1944), but did not describe the variation during development (Padget 1948). We speculate that Padget might exclude samples with such variations in $\mathrm{CW}$ in the latter study to 
demonstrate the natural development of $\mathrm{CW}$ or might not meet such samples as she described in the limited number of samples.

The ACOM may close in later stages, as its formation is the final step in completing the $\mathrm{CW}$, according to the previous study by Padget. It is also possible that the $\mathrm{CW}$ remains unclosed at the $\mathrm{ACOM}$ until birth, as such a variation is known to exist in adults (Alpers et al. 1959; Eftekhar et al. 2006; Fawcett \& Blachford 1905; Fisher 1965; Fujimoto \& Tanaka 1989). A similar interpretation can be considered for samples in which the $\mathrm{CW}$ remained unclosed at the PCOM and $\mathrm{P} 1$, suggesting this may remain so until birth. Previous studies indicate that the blood supply from ICA to PCA through PCOM, supplying the cerebellum and brain stem, may decrease during embryonic development owing to the growth of the prosencephalon (cerebrum) (Okahara et al. 2002; Van Overbeeke et al. 1991). The blood supply to the PCA territory is compensated by the BA. However, an unclosed CW owing to aplasia or hypoplasia of PCOM results in restricted collateral flows, and, is a recognized risk factor for cerebrovascular conditions such as ICA occlusion, border zone infarcts, transient ischemic attacks, and minor strokes (Hendrikse et al. 2001). Variations, in the form of 
aplasia or hypoplasia of $\mathrm{P} 1$, result in the ICA providing blood supply to the PCA. This condition is referred to as the fetal posterior cerebral artery (fetal type) (Raamt et al, 2006). In the fetal type of CW, the entire PCA territory depends on the ICA for its blood supply, while the other areas, including cerebellum and brain stem, depend on the BA for their blood supply. The communication of the $\mathrm{CW}$ at $\mathrm{P} 1$ has a significant influence on intracranial hemodynamics (Wentland et al. 2010). The present study, however, suggests the possibility that the variations in ACOM, PCOM, and P1 may occur during embryonic development itself. Such variations may have a significant influence on the development and growth of the brain, and affect its morphology as well as function (Raybaud 2010; Wentland et al. 2010). The present study indicates that the CW is closed around CS 22, one or two stages later than previously reported (Padget 1948). Thus, the frequency of variations in the CW at CS 23 , at the end of the embryonic stage, and its comparison with the frequency of variations after birth need to be investigated in future studies.

\section{Acknowledgements}


This study was supported by Grant Nos. 25461642, 24119002, 26220004, 15H01119,

$15 \mathrm{~K} 08134,15 \mathrm{H} 05270,15 \mathrm{H} 01121$, and $15 \mathrm{~K} 15014$ from the Japan Society for the

Promotion of Science.

Disclosures

None

\section{References}

Alpers BJ, Berry RG, Paddison RM. 1959. Anatomical studies of the CW in normal brain.

AMA Arch Neurol Psychiatry 81:409-418.

Blackburn IW. 1907. Anomalies of the encephalic arteries among the insane. A study of the arteries at the base of the encephalon in two hundred and twenty consecutive cases of mental disease, with special reference to anomalies of the CW. J Comp Neurol Psychol 17:493-517.

Blackburn IW. 1910. On the median anterior cerebral artery as found among the insane.

J Comp Neurol Psychol 20:185-194.

Dyste GN, Beck DW. 1989. De novo aneurysm formation following carotid ligation.

Case report and review of the literature. Neurosurgery 24:88-92. 
Eastcott $\mathrm{HH}$. The beginning of stroke prevention by surgery. 1994. Cardiovasc Surg

2:164-169.

Eftekhar B, Dadmehr M, Ansari S, Ghodsi M, Nazparvar B, Ketabchi E. 2006. Are the distributions of variations of CW different in different populations? - Results of an anatomical study and review of literature. BMC Neurology 6: 22.

Fisher CM. 1965. The CW: anatomical variations. Vasc Dis 2:99-105.

Fujimoto K, Tanaka O. 1989. Morphological examination of the circulus arteriosus cerebri humani $(\mathrm{CW})$. I. Anterior and posterior communicating arteries. Kaibogaku Zasshi 64:481-489.

Hashemi SMR, Mahmoodi R, Amirjamshidi A. 2013. Variations in the anatomy of the Willis circle: A 3-year cross-sectional study from Iran (2006-2009). Are the distributions of variations of circle of Willis different in different populations? Result of an anatomical study and review of literature. Surg Neurol Int 4:65.

Horikoshi T, Akiyama I, Yamagata Z, Sugita M, Nukui H. 2002. Magnetic resonance angiographic evidence of sex-linked variations in the CW and the occurrence of cerebral aneurysms. J Neurosurg 96:697-703.

Kayembe KN, Sasahara M, Hazama F. 1984. Cerebral aneurysms and variations in the 
CW. Stroke 15:846-50.

Kirgis HD, Fisher WL, Llewellyn RC, Peebles EM. 1966. Aneurysms of the anterior communicating artery and gross anomalies of the CW. J Neurosurg 25:73-78.

Kwak R, Ohi T, Niizuma H, Suzuki J. 1980. Afferent artery and the site of neck of anterior communicating aneurysms. Surg Neurol 13:221-223.

Hendrikse J, Hartkamp MJ, Hillen B, Mali WP, van der Grond J. 2001. Collateral ability of the $\mathrm{CW}$ in patients with unilateral internal carotid artery occlusion: border zone infarcts and clinical symptoms. Stroke 32:2768-2773.

Nishimura H, Takano K, Tanimura T, Yasuda M. 1968. Normal and abnormal development of human embryos: first report of the analysis of 1,213 intact embryos. Teratology 1:281-290.

Okahara M, Kiyosue H, Mori H, Tanoue S, Sainou M, Nagatomi H. 2002. Anatomic variations of the cerebral arteries and their embryology: a pictorial review. Eur Radiol 12:2548-2561.

Padget DH. 1948. The development of the cranial arteries in the human embryo. Contr Embryol 12:205-261. 
Padget DH. 1944. The circle of Willis: Its embryology and anatomy. In Dandy WE (ed)

Intracranial arterial aneurysms. Comstock Publishing Co, New York, 67-90.

Raybaud C. 2010. Normal and abnormal embryology and development of the intracranial vascular system. Neurosurg Clin N Am 21:399-426.

Van Overbeeke JJ, Hillen B, Tulleken CA. 1991. A comparative study of the CW in fetal and adult life: the configuration of the posterior bifurcation of the posterior communicating artery. J Anat 176:45-54.

van Raamt AF, Mali WP, van Laar PJ, van der Graaf Y. 2006. The fetal variant of the CW and its influence on the cerebral collateral circulation. Cerebrovasc Dis 22:217224.

Vrselja Z, Brkic H, Mrdenovic S, Radic R, Curic G. 2014. Function of CW. J Cereb Blood Flow Metab 34:578-584.

Schomer DF, Marks MP, Steinberg GK, Johnstone IM, Boothroyd DB, Ross MR, Pelc NJ, Enzmann DR. 1994. The anatomy of the posterior communicating artery as a risk factor for ischemic cerebral infarction. N Engl J Med 330:1565-1570. 
Shiota K. 1991. Development and intrauterine fate of normal and abnormal human

conceptuses. Congenit Anom (Kyoto) 31:67-80.

Wentland AL, Rowley HA, Vigen KK, Field AS. 2010. Fetal origin of the posterior cerebral artery produces left-right asymmetry on perfusion imaging. AJNR Am J Neuroradiol 31:448-453.

Yamada S, Uwabe C, Fujii S, Shiota K. 2004. Phenotypic variability in human embryonic holoprosencephaly in the Kyoto Collection. Birth Defects Res A Clin Mol Teratol 70:495-508.

\section{Figure legends}

\section{Figure 1. Formation of the CW during Carnegie stages 20 and 23}

* in CS20; Left and right ACA was not connected. Acom was not formed.

Figure 2. Variations in the CW at Carnegie stage 21.

(A) The circle is unclosed at ACOM and bilateral PCOM.

(B) The circle is unclosed at left PCOM and right P1. ACOM, anterior communicating artery; PCOM, posterior communicating artery; ACA, anterior cerebral arteries; ICA, internal carotid arteries (ICA); PCA, posterior cerebral arteries; BA, basilar artery; P1, 
$P 1$ segment of $P C A$ 
Table1. Formation of the circle of Willis

\begin{tabular}{|c|c|c|c|c|c|c|}
\hline \multirow{2}{*}{$\begin{array}{l}\text { Carnegie } \\
\text { stage }\end{array}$} & \multirow{2}{*}{$\begin{array}{l}\text { No of } \\
\text { samples }\end{array}$} & \multicolumn{2}{|c|}{ Circle formation } & \multicolumn{3}{|c|}{ Segments at which the circle was unclosed } \\
\hline & & Closed & Unclosed & ACOM alone & $\mathrm{ACOM}+\mathrm{b} / \mathrm{P} 1$ & PCOM + others \\
\hline 20 & 6 & 1 & 5 & 4 & 1 & 0 \\
\hline 21 & 8 & 2 & 6 & 2 & 1 & $\begin{array}{l}\text { ACOM + Lt. PCOM, 1; } \\
\text { Lt. PCOM + Rt. P1, 1; } \\
\text { Rt. PCOM + Rt. P1, } 1\end{array}$ \\
\hline 22 & 3 & 2 & 1 & 0 & 1 & 0 \\
\hline 23 & 3 & 2 & 1 & 0 & 1 & 0 \\
\hline Total & 20 & 7 & 13 & 6 & 4 & 3 \\
\hline
\end{tabular}

ACOM, anterior communicating artery; PCOM, posterior communicating artery; P1, P1 segment of posterior cerebral artery; Rt., right; Lt., left; b/l, bilateral 

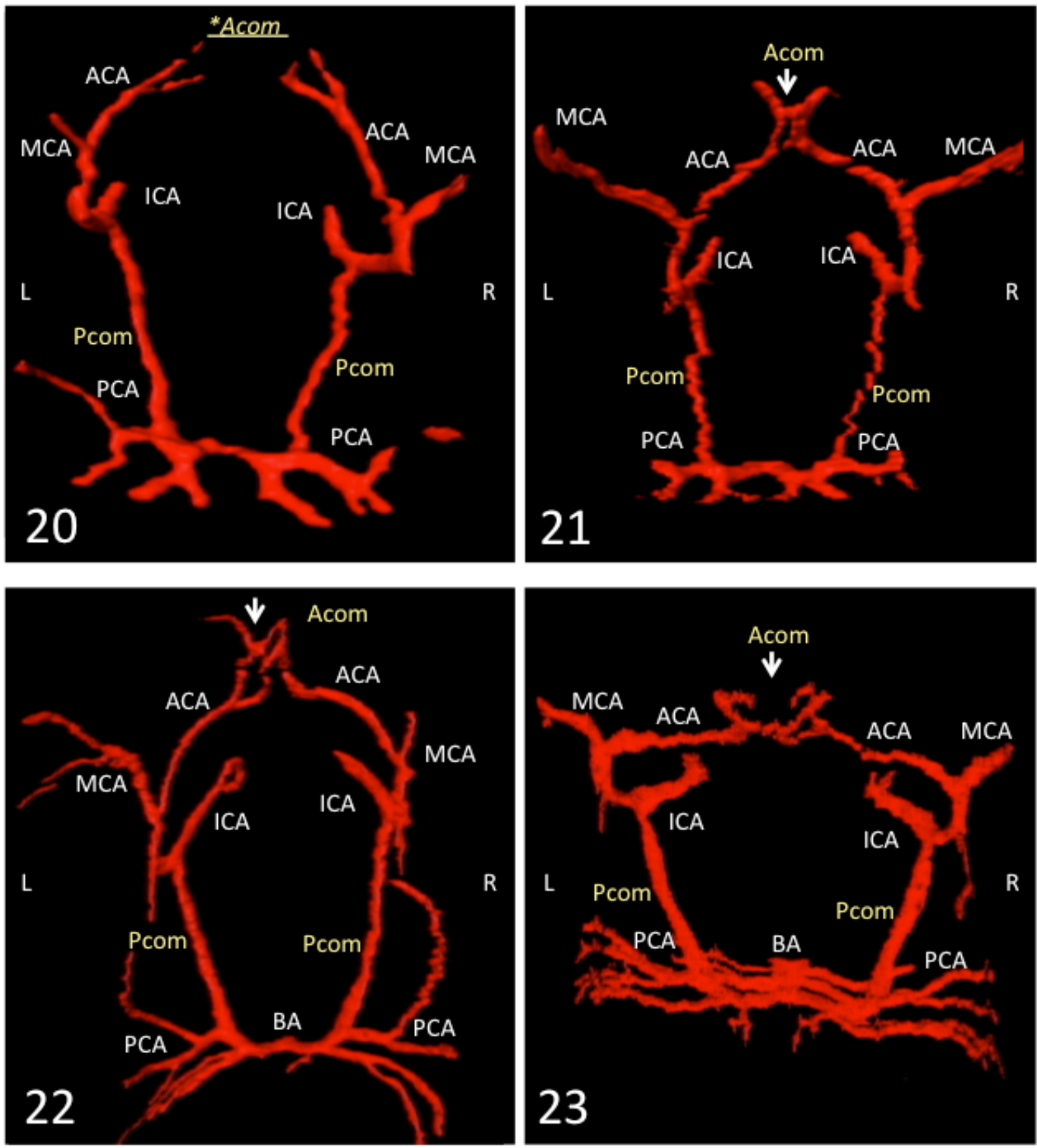


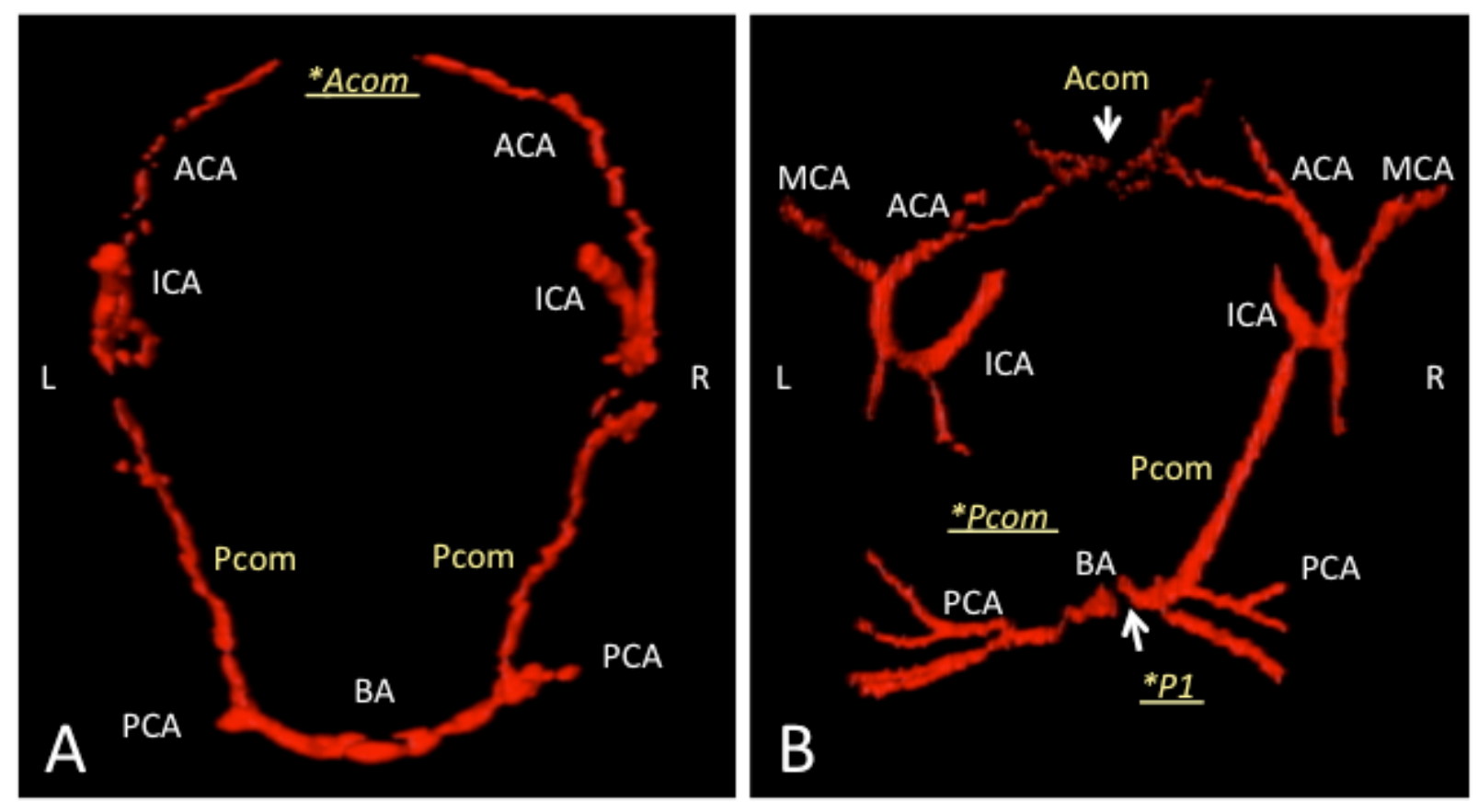

